\title{
Entre a obra e a imagem: a sobrevivência da escultura Mademoiselle Pogany II de Constantin Brancusi
}

RESUMO: Este texto aborda algumas questões a cerca da produção discursiva entre a imagem, a obra e a história da arte associada ao processo de reconstrução do acervo do MAM RJ pós-incêndio, a partir da sobrevivência de uma de suas obras mais relevantes, a escultura Mademoiselle Pogany II de Constantin Brancusi.

PALAVRAS-CHAVE: obra de arte, imagem, museu

ABSTRACT: This text discusses some issues about the discursive production of the image, the work and the history of art associated with the process of reconstruction of the collection of the MAM RJ post-fire from the survival of one of his most important works, sculpture Mlle. Pogany II Constantin Brancusi's.

KEYWORDS: work of art, image, museum

*Ana Chaves é Doutoranda em História e Crítica da Arte pelo Programa de Pós-graduação em Artes Visuais da Escola de Belas Artes da Universidade Federal do Rio de Janeiro. 
Na madrugada de oito de julho de 1978, um grande incêndio atingiu o bloco de exposições do Museu de Arte Moderna do Rio de Janeiro. O acontecimento foi alardeado pelos meios de comunicação que lamentavam a perda de noventa por cento do acervo incluindo a Coleção MAM, grande parte da biblioteca e cerca de duzentas obras que compunham a exposição "Arte Agora III - América Latina: Geometria Sensível" com organização do crítico de arte Roberto Pontual.

O jornal A Gazeta publicou uma nota lamentando a tragédia, mas colocou em questão a quantidade de diretores de museu em todo mundo que não gostariam de ter a chance de fazer "tabula rasa", recomeçar, "eliminar imensos estoques de quadros indesejáveis e, iniciar uma nova coleção de arte, orientada tecnicamente para o melhor, adquirindo só peças excepcionais, e exibir ocupando o mínimo de espaço, o acervo ideal."( A GAZETA, 1978).

A nota não está assinada, portanto não sabemos se foi escrita por um jornalista ou crítico. Mesmo 'anônima', o trecho citado nos chama a atenção para as expressões "acervo ideal," "tecnicamente para o melhor", "peças excepcionais," "ocupando o mínimo de espaço". Pensando o contexto em que esse texto foi publicado e o momento artístico, ou seja, o final da década de 1970, nos indagamos: Como se mede um acervo ideal? Como se mede a 'excepcionalidade' de uma obra de arte? É possível imaginar essa 'excepcionalidade' no conjunto de obras sobreviventes ao incêndio? Estariam estas obras enquadradas nesse 'ideal'?

Mesmo com a perda de praticamente toda coleção, um grupo de obras resistiu às altas temperaturas. O restaurador Edson Motta à época do incêndio, percorreu todo o salão de exposições a procura de fragmentos de obras que apresentassem resquícios de pigmentação, para que pudessem ser restauradas e arquivadas como documento para posterior investigação do historiador. ${ }^{1}$ Como registro histórico, alguns desses vestígios foram armazenados e com o avanço das técnicas de restauração e, sobretudo mediante o apoio financeiro, algumas obras puderam ser completamente recuperadas. ${ }^{2}$

Notamos a impossibilidade de reconstruir a história do acervo tal como foi concebido diante da constatação do historiador David Lowenthal: "o próprio fato de o passado ser passado impede sua total reconstrução"( LOWENTHAL, 1998, p. 111). Por outro lado, podemos interpretar os relatos orais, escritos e imagéticos como possíveis marcos temporais deflagradores de uma escrita da história do acervo do MAM. Contudo, mesmo que tivéssemos um arsenal 
de fontes que relatassem a sua história até o momento do incêndio, não conseguiríamos recuperar a sua totalidade, afinal o passado não é construído apenas de relatos, mas também de eventos, situações e acontecimentos.

Os relatos podem ser comparados entre si e constituir uma história, não como um retrato que se desenha tal qual o modelo, mas uma construção narrativa, segundo os interesses de quem a cria: "o passado que conhecemos ou vivenciamos está sempre dependente de nossas próprias opiniões, perspectivas e, acima de tudo, de nosso próprio presente." (LOWENTHAL, 1998, p. 113) Desse modo, o conhecimento sobre o passado é construído com base na interação entre as fontes, os saberes e o contexto de quem o produz, pois "uma coisa é o fato acontecido, outra coisa é o fato escrito." 3

A história do MAM é constituída também por imagens e por seu intermédio é possível identificar parte do acervo sobrevivente. Para o historiador da arte, não basta relatos escritos. As imagens podem assumir relatos, ditos visuais, essenciais para restituir ou desconstruir a história de uma obra. Para a restauração, é possível recompor uma obra, através da análise minuciosa dos vestígios materiais, pictóricos, e compara-las a algum registro fotográfico realizado enquanto permanecia íntegra. No entanto, para o historiador da arte, interessa 'restaurar' as narrativas sobre a obra à sua 'imagem e semelhança'?

O conhecimento sobre o passado é construído com base na interação entre as fontes, os saberes e o contexto de quem o produz. Para os historiadores, a natureza temporal das coisas difere da temporalidade definida pela história escrita, pelos usos dos tempos verbais que demarcam a relação entre o passado e o presente. Na concepção de Didi-Huberman essa perspectiva alia a escrita da história à inevitável prática do anacronismo, configurando, portanto, um paradoxo na forma tradicional de se praticar a disciplina que sempre rejeitou tal condição. Considera o historiador um "fictor", um autor e inventor do passado, que deve estar sempre consciente das armadilhas das certezas, sobretudo sendo a arte seu objeto de estudo.

Temos ainda alguns monumentos, mas não sabemos mais o mundo que os exigia; temos ainda algumas palavras, mas não sabemos mais a enunciação que as sustentava; temos ainda algumas imagens, mas não sabemos mais os olhares que the davam carne; [...] O que isso quer dizer? Que todo passado é definitivamente anacrônico: só existe, ou só consiste, através das figuras que dele nos fazemos; [..](DIDI-HUBERMAN, 2013, p. 50). 
As obras que sobreviveram ao incêndio poderiam ser descritas com base em fontes de época, interpretadas com as categorias já estabelecidas pela história da arte. No entanto, ao compreender que a imagem é fruto de uma montagem de tempos heterogêneos e a narrativa histórica é construída não por meio de um arsenal de informações fruto de fontes rígidas do passado, mas por sua virtude dialética. O caráter atemporal e descontínuo da imagem se reconfigura à medida em que é enquadrado em alguma narrativa determinada por escolhas metodológicas. Entendendo que toda e qualquer narrativa implica uma seleção e, portanto, uma avaliação do que interessa ou não ser exposto.

Com o intuito de verificar quais obras de arte representam determinado momento da produção artística, as narrativas lineares e cronológicas são constantemente utilizadas pelas comissões de acervo para identificar lacunas históricas que poderiam ser incorporadas à uma coleção geralmente orientada por uma determinada narrativa histórica da arte. Assim como bem nos lembra, o historiador da arte Hans Belting : "Não existe nenhum debate em torno do museu que também não seja um debate em torno da ideia remanescente de história da arte." (BELTING, 2012, p. 174). Com um teor panorâmico e organizada em núcleos históricos, o recorte curatorial de uma coleção acompanha o perfil discursivo da própria história da arte também panorâmico e excludente.

Segundo a historiadora e antropóloga Chantal Georgel (2015), foi na metade do século XIX que os museus herdariam os princípios de classificação dos primeiros historiadores da arte. Substituiriam as organizações aleatórias por uma organização que privilegiasse um tipo de composição que pudesse narrar a trajetória da arte e sua dimensão evolutiva, segundo as concepções clássicas, à época de Vasari e Winckelmann. Contudo, a autora questiona se teria o museu a função de tornar-se um lugar da história, já que a maioria dos acervos foram constituídos por coleções privadas, geralmente orientadas pelo gosto do colecionador. Por outro lado, reconhece nessa aparente liberdade de escolha, a oportunidade de conhecer obras que não estariam, de certo modo, submetidas às determinadas hierarquizações do campo da arte.

Muitos colecionadores ampliavam constantemente sua coleção, com o objetivo exclusivo de doá-la ao museu. O volume de coleções nos museus, organizadas segundo uma lógica cronológica, contribuiu para a formulação de uma visão histórica, enciclopedista, universalista da arte. Condição que norteou cada vez mais o interesse dos colecionadores em formar um patrimônio artístico representativo de uma história geral da arte. Embora não houvesse inicialmente a 
intenção de adquirir obras, segundo os parâmetros estabelecidos por um connoisseur, já havia, de certo modo, um tipo de seleção e predileção por determinados artistas e obras que, inseridas em um determinado conhecimento, estariam eleitas sob um determinado saber.

É recursivo o exercício de categorização das obras a fim de que se identifiquem quais representantes de determinado estilo ou movimento estão contemplados na coleção e quais 'categorias' precisam ser ainda preenchidas. Muitos curadores argumentam sobre a aquisição de obras estar associada, sobretudo ao preenchimento de lacunas históricas em um acervo. Desse modo, o exercício de preencher lacunas foi uma necessidade cada vez mais recorrente dos museus, que passariam a organizar seu acervo segundo uma lógica de enquadramento baseada em um modelo tradicional de história da arte. É possível imaginar que antes mesmo da instituição da disciplina, já havia uma espécie de 'história da arte' antes da história da arte nos museus. A diferença estaria nos seus propósitos, que inicialmente, não teriam o compromisso em representar um determinado período da história da arte, embora estivesse ali, implícito nos seus acervos. Segundo CHANTAL (2015, p.278) o museu tinha como propósito afirmar a "supremacia da nação, propagar o amor à arte, refinar o gosto, fornecer modelos aos artistas." Posteriormente, com a institucionalização da disciplina na França no final do século XIX e a criação da École du Louvre, os acervos estariam cada vez mais submetidos a exploração de seu conteúdo para fins educacionais, gerando os primeiros cursos de história da arte.

Segundo o relato de Irma Arestizabal, ${ }^{4}$ responsável pelo acervo do MAM no período da gestão de Paulo Herkenhoff, o objetivo prioritário era oferecer ao público visitante uma dimensão historiográfica da arte através de um núcleo dominante, "um grupo restrito de obras, mais representativas do acervo, que ficará em exposição permanente, se convertendo em um símbolo do museu [...]" (ARESTIZABAL, 1987). Para a curadora, o Museu organizaria seu acervo a partir de um 'centro' inspirado pelo utópico projeto Museu de Crescimento llimitado (1930) de Le Corbusier onde o acervo se desenvolveria a partir de um núcleo podendo crescer infinitamente.

A escultura Mademoiselle Pogany II, 1920, de Constantin Brancusi foi uma das obras que sobreviveu ao incêndio e compõe o grupo de obras representativo mencionado pela curadora. É frequentemente exibida na condição de highlight junto a outras obras que também resistiram ao incêndio. De acordo com as informações técnicas relativas à procedência da obra, consta no inventário da Coleção MAM que o casal Stella e Roberto Marinho adquiriu a escultura do artista e a doou em 1952, ano de reabertura do Museu no térreo do Palácio Gustavo Capanema, antigo Ministério da Educação e Saúde. 


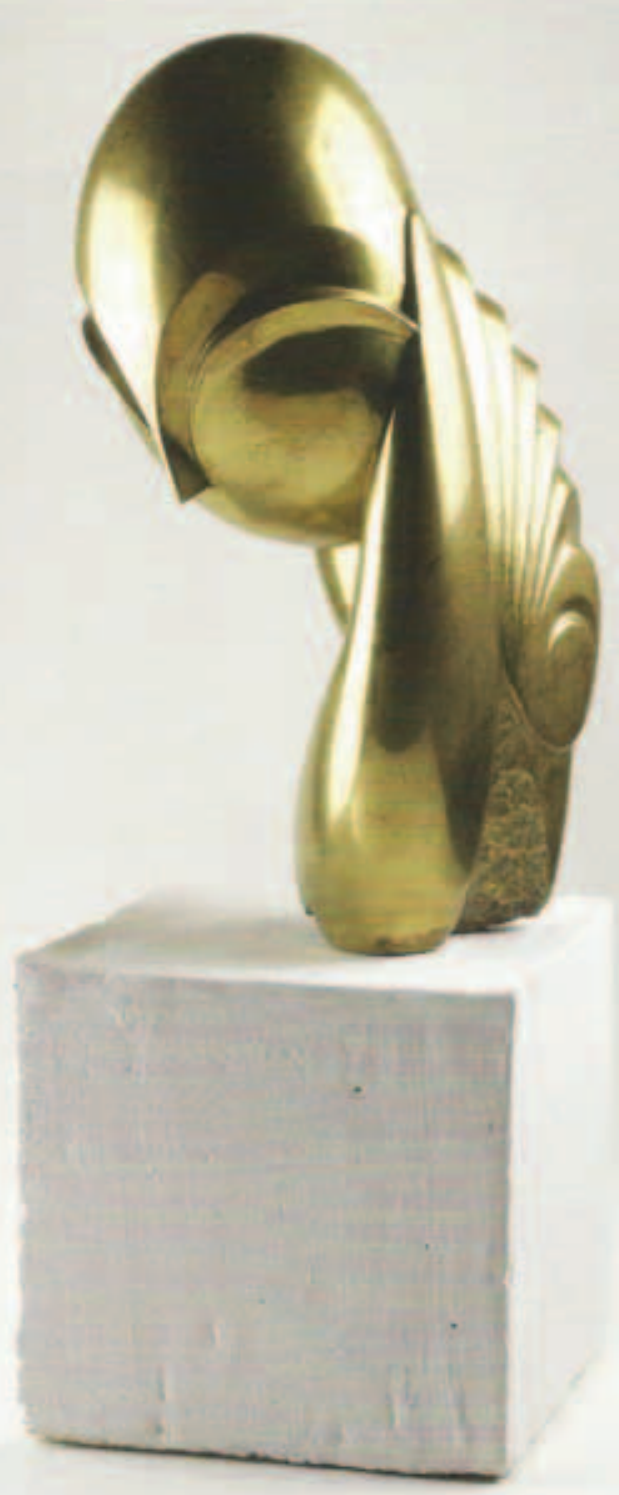

Constatin Brancusi

MIle. Pogany II, 1920, Bronze. Coleção MAM 
Um pequeno catálogo da Coleção, editado em 1953, apresenta a imagem da escultura em preto e branco ao lado de um breve biografia do artista e alguns comentários sobre a forma síntese do "ovóide" como matriz de seu pensamento plástico junto ao "polido da matéria" que revela uma obsessão e um apego do artista às exigências de determinados materiais. Por fim, cita uma frase de Brancusi em que afirma ser sua obra uma aproximação "do sentido real das coisas"(MAM, 1953 p. 17). Somente em 1999, a imagem da escultura volta a ser exibida em um catálogo do acervo, dessa vez sob um outro ângulo, em cores, junto a uma breve análise da obra do artista em que constata "consistência e uma alta dose de originalidade a lição cubista", além de considerar sua influência para a escultura moderna como uma "espécie de equivalente escultural" de Picasso (MAM, 1999, p. 276).

Ao buscarmos em outras fontes um breve histórico da escultura Mlle. Pogany, descobrimos que esta escultura ocupou Brancusi por quase vinte anos. Criada a partir do encontro do artista com a jovem estudante de arte húngara Margit Pogany recém chegada a cidade de Paris. A primeira versão foi esculpida em mármore em 1912 e consta atualmente no acervo do Philadelphia Museum of Art junto a um desenho em grafite e carvão com efeito de esboço para a escultura. Outras obras do artista constam no acervo como a terceira versão de Mlle. Pogany III, 1931; The Kiss, 1916; Bird in Space, 1924; Danaïde, 1913 entre outras. Exposta pela primeira vez na Armory Show (1913) causou polêmica entre os visitantes e a imprensa ao associar a escultura ao retrato de uma mulher. ${ }^{5}$

Segunto relatos, Margit posou para Brancusi diversas vezes em seu ateliê, no entanto foi na sua ausência que a escultura foi, enfim, criada. É possível constatar algumas semelhanças ao observar seu autorretrato, que também compõe o acervo do Museu, e perceber algumas características da modelo, principalmente no detalhe dos grandes olhos e no gesto das mãos impressos na escultura. ${ }^{6}$

Ao longo dos anos, a Mlle. Pogany sofreu simplicações até às últimas versões, incluindo a do MAM, com maior abstração das referências iniciais. Outras versões da escultura estão no Musée National d'Art Moderne - Centre Georges Pompidou e no Museum of Modern Art de Nova York. Em ambos os museus, a obra é apresentada de forma semelhante, em que a biografia do artista, a relação com Margit e a polêmica na exposição Armory Show são assuntos recorrentes. 
Para Didi-Huberman (2015), o historiador da arte ao reproduzir um discurso em que a obra é interpretada segundo os registros, os documentos, as fontes "historicamente pertinentes", estaria realizando uma interpretação "eucrônica", ideal, portanto idealizada do passado. Nesse sentido, podemos afirmar que a constituição de um "acervo ideal", provém da ideia de um museu que reitera e apenas reproduz a legitimidade dos discursos sobre as obras, sem, no entanto, suscitar novas questões sobre as mesmas já que pertencem a um acervo, portanto a um contexto específico. Consideramos que a própria materialidade da obra de arte, contribuiria com evidências que nos conduziriam a novas possibilidades discursivas, para além daquelas comumente utilizadas para contextualizar uma obra em uma coleção de arte.

É possível encontrar a imagem da escultura Mlle. Pogany em diversas situações e materiais: em exposição, no ateliê do artista, representada em gesso, bronze, mármore. Mas a imagem que talvez, tenha nos chamado mais a atenção, é a que está reproduzida na capa da revista Arte Hoje, ${ }^{7}$ edição de agosto de 1978, um mês após o incêndio, onde apareceu junto a seguinte frase: "O MAM renascerá" com grande parte da sua superfície decomposta em virtude do incêndio. Na imagem, a estrutura da escultura aparenta íntegra, rígida, tornando-se, portanto, segundo a própria revista, o símbolo da reconstrução do Museu pós-incêndio.

O leque de possibilidades discursivas que a imagem da escultura nos oferece, mobiliza nosso olhar sobre a imagem, sobre o tempo e sobre as possibilidades teóricas que o seu conteúdo nos oferta. Podemos afirmar que esta imagem não pertence a um só tempo, mas é fruto de uma confrontação de tempos distintos. Estar diante desta imagem não é simplesmente estar diante de esquematismos estilísticos, arranjos formais e estetizantes, mas perceber a rede complexa de relações que a constitui. Ao contrário de outras imagens que retratam o incêndio, onde as obras são identificadas em meio as fuligens e destroços, esta obra aparece na capa da revista tal qual a página de um livro de história da arte: em destaque sobre um fundo branco. O que fazer diante dessa imagem? Como interpretá-la?

Ao interrogar a imagem, interrogamos o nosso próprio conhecimento. E no momento em que percebemos que o que sabemos não é suficiente para avançarmos em novas interpretações, percebemos a necessidade de deslocarmos nosso olhar a fim de iniciar uma investigação que resultará em um novo modo de se relacionar com a história da arte. 
Mlle. Pogany II é a obra que sobreviveu ao incêndio. Ela 'fala' desse lugar. Como contar essa história? A estreita ligação da história da arte com o museu, nos oferece possibilidades de uma investigação que por meio das obras sobreviventes, podemos repensar as categorias que as emolduraram como arte e as localizaram no MAM segundo um modelo canônico de uma história da arte, formalista, progressiva e linear. Porém, com o incêndio, a linha se rompe, as obras se transformam e disparam um modo de análise do conjunto das obras sobreviventes em sua dimensão fenomenológica, conceitual, material, temporal a partir da consideração de que "tudo muda no acontecimento, e nós mudamos no acontecimento" (DELEUZE; GUATARRI, 1992, p. 134) e, sobretudo mudamos diante de um acontecimento. As impressões do incêndio constam nas obras. Elas, de algum modo, mesmo restauradas, exibem essa experiência, pois há na sua própria materialidade a memória desse episódio. ${ }^{8}$

Não podemos, então, num caso como esse, nos contentarmos em fazer a história de uma arte sob o ângulo da "eucronia", isto é, sob o ângulo conveniente do "artista e seu tempo". O que tal visualidade exige é que seja vista sob o ângulo de sua memória, de suas manipulações do tempo, [...] (DIDI-HUBERMAN, 2015, p. 26).

O escritor francês Marcel Proust no livro Em busca do tempo perdido [1913], após narrar a experiência com a madeleine, intrigado, questiona a origem da sensação, o caminho percorrido pelas lembranças que não estão mais presentes nos estímulos externos, no chá ou no biscoito, mas nele mesmo. Interroga seu espírito sobre a verdade, mas contata a "região obscura" que deverá ultrapassar, já que todo o conhecimento que tem acumulado de nada adiantaria: "Procurar? Não apenas: criar. Estar diante de algo que ainda não existe e que só ele pode tornar real, e depois fazer entrar na sua luz." (PROUST, 2014, p. 72).

Para Sigmund Freud, o material que de fato constitui a memória, "estaria sujeito, de tempos em tempos, a um rearranjo segundo novas circunstâncias - a uma retranscrição, [...] a memória não se faz presente de uma só vez, mas se desdobra em vários tempos; [...]"( FREUD, 1996). Desse modo, há um jogo entre esquecimento e lembrança, prórprio do trabalho da reminiscência, em que o que se revela mais importante é o tecido da rememoração onde todo o "acontecimento vivido é finito, ou pelo menos encerrado na esfera do vivido, ao passo que o acontecimento lembrado é sem limites, porque é apenas uma chave para tudo o que veio antes e depois." (BENJAMIN, 1986, p. 37). 
Mesmo com o trauma do incêndio aparentemente superado, o MAM reconstruído e o acervo renovado, a descoberta da imagem da Mlle. Pogany desloca as narrativas esgotadas sobre a obra, sobre a história da obra no Museu, portanto sobre as experiências que compõe sua memória. Assim como expõe Benjamin, "antes que a imagem ameace desaparecer"9 este estado de agitação refere-se à demanda do pesquisador em abandonar a tranquila atitude contemplativa à constatação crítica que a emergência do fragmento do passado coincide com o momento preciso encontrado no presente. É preciso, nesse sentido, se desvencilhar dos regimes temporais estabelecidos pela historiografia da arte reforçada invariavelmente, para investigar a memória da obra, não como um arquivo de fatos, datas e nomes, mas os acidentes, as fissuras, as excessões, os intervalos que possam habitar o conteúdo da sua imagem.

Assim como alguns importantes artefatos descobertos por meio de escavações em ruínas transformam-se em relíquias, a escultura de Brancusi estaria, de certo modo, relacionada também a essa condição. Afinal representa o MAM. A escultura incorpora a história desse lugar. Mlle. Pogany é a obra que sobreviveu ao incêndio. É testemunha ocular. Como contar essa história? Como narrar a simultaneidade temporal impressa nesta obra? Afinal a escultura representa o MAM e um renascimento duplo: do Museu e da obra.

A imagem pode nos oferecer uma crônica do que está perdido ou prestes a perder-se na história: "o cronista que narra os acontecimentos, sem distinguir entre os grandes e os pequenos, leva em conta a verdade de que nada do que um dia aconteceu deve ser considerado como perdido para a história." ${ }^{10}$ Ao invés de tratá-la como um simples documento histórico, por que não considerá-la um objeto de estudo potencial à disciplina? Apropriar-se desta imagem é como revolver um arquivo até o momento mantido em perfeita ordem, assim como nos alerta Didi-Huberman: "[...] é preciso atrever-se, é preciso acercar o rosto à cinza. E soprar suavemente para que a brasa, sob as cinzas, volte a emitir seu calor, seu resplendor, seu perigo." Portanto, é preciso aproximar-se da obra e perceber sua voz que se eleva e que clama: "Não vês que ardo?" (DIDI-HUBERMAN,2012, p.216).

Se o aspecto da escultura de Brancusi pós-incêndio fosse preservado, sua condição se assemelharia às estátuas mutiladas encontradas em descobertas arqueológicas, que incorporadas ao museu, passam a ser celebradas com profunda admiração: “[...] muitas vezes preferimos as estátuas de Lagash sem cabeça, os budas kmeres sem pernas, as feras assírias isoladas. 0 acaso quebra e o tempo metamorfoseia."( MALRAUX, 2015, p. 182). 
Podemos considerar que parte do acervo, sobretudo as obras sobreviventes restauradas ou não 'sofrem de reminiscências', desafiam o contínuum da história ${ }^{11}$ e, portanto, a finalidade do museu em conservar o conteúdo da obra de arte claramente orientado por uma concepção positivista da história da arte dos estilos, dos enquadramentos. Concepção que reitera a abordagem secular de Winckelmann que ao reunir, organizar, analisar e decompor o material disperso da Antiguidade, prescreveu uma história da arte segundo uma perspectiva biológica, evolucionista, obedecendo às leis naturais da vida e da morte, do declínio e decadência. A exemplo dessa perspectiva, Didi-Huberman [2002] o cita: "o objeto de uma história ponderada da arte é remontar a sua origem [Ursprung], acompanhar seus progressos [Wachstum] e variações [Veränderung] até sua perfeição, e marcar sua decadência [Untergang] e queda [Fall] até sua extinção"( DIDI-HUBERMAN, 2013, p.19).

A afirmação das transformações pelas quais passam algumas obras de arte estão condicionadas a um regime de gosto e estilo segundo uma concepção de arte definida por cada época. $O$ enquadramento dado a obra de Brancusi nos aproxima da imagem como vestígio, na medida em que amplia ou altera o próprio conteúdo da obra de arte e consequentemente o saber histórico sobre a mesma. Descaracterizada dos atributos dos quais a consagrou, a imagem da escultura carrega uma história própria, um feixe de significados que embora subjetivos, a nosso ver, apresenta uma importância tal qual os princípios estéticos que a certificaram. A sobrevivência da escultura e, sobretudo de sua aparência tal como foi encontrada reforça, a nosso ver, a sua própria existência, a manutenção de sua vivacidade diante de contemplações estéreis recorrentes no interior do museu.

Após o incêndio, algumas obras de arte ganharam uma 'sobrevida', um acréscimo de tempo que altera a história cristalizada que a constituía. É como se o incêndio e toda a fabulação em torno do renascer das cinzas, despertasse a condição da obra para o que de fato interessava ao artista, revelar o estado real das coisas. O aspecto do bronze expõe sua concretude, sua fisicalidade, um retorno à corporalidade da matéria às lembranças de seu estado original. $E$ isto, não pressupõe uma fetichização do objeto, pelo contrário, nos alerta para a mortalidade da obra e de um tipo de discurso postulado por verdades estabelecidas pela história da arte. Desse modo, não seria esta imagem um sintoma? Uma imagem crítica, reveladora de uma intensidade plástica, onde o grau de deformação inquieta promove uma abertura dos campos discursivos aplicados à obra. Não seria o momento de considerarmos a possibilidade de 
escovarmos a história a "contrapelo" como propõe Benjamin [1940], assumindo um modelo dialético de história da arte, cuja excepcionalidade esteja presente justamente no rastro do que restou do incêndio?

Artigo recebido em julho de 2016 e aprovado em agosto de 2016.

\section{Notas}

1 “Nos casos em que a tela foi parcialmente destruída pelo fogo, não há restauração possível e só recuperamos a parte não atingida, que fica como documento. Até um terço de uma obra deve ser salvo e mantido." (Motta apud Noronha, 2014, p. 6).

2 Como ocorreu com a obra “Composição,"1952 de Lygia Clark. Danificada pelo fogo e pela água, com várias perdas pictóricas e estruturais, foi restaurada trinta e quatro anos após o incêndio entre outras obras através do projeto “Restauração de parte da Coleção do MAM anterior a 1978" contemplado pelo Programa Pró-Artes Visuais da Prefeitura do Rio de Janeiro em 2012.

3 Trecho da fala de Antonio Biá, personagem do filme Narradores de Javé de Eliane Caffé (2004).

4 Irma Arestizabal (1940-2009) foi crítica de arte e professora da Universidade de Buenos Aires, curadora das Coleções do Museu de Arte Moderna Rio de Janeiro no período de 1986-1990 e diretora do Centro Cultural da Pontifícia Universidade Católica do Rio de Janeiro em 1980-1992.

5 http://armory.nyhistory.org/mlle-pogany-i/ Acesso 10 fev 2016.

6 "The clay studies that he made in her presence were destroyed every time, though several drawings survive (see Philadelphia Museum of Art, 1947-88-10). After she returned to Hungary, he carved this marble portrait head from memory." Disponível em http:// www.philamuseum.org/collections/permanent/44648.html Acesso 12 fev 2016.

7 Arte Hoje foi uma revista voltada para as artes plásticas, arquitetura e outros temas. Lançada em julho de 1977 pela Editora Globo, permaneceu nas bancas até o ano de 1979 com aproximadamente trinta títulos lançados. Editada pelo jornalista Milton Coelho da Graça e pelo crítico de arte Wilson Coutinho que ocuparia na década de 1990 a função de curador do MAM RJ.

8 "Mademoiselle Pogany de Brancusi já está exposta no segundo andar, exibindo na cabeça uma pequena 'cicatriz'." O MAM está de volta com a promessa de vida nova. O Globo: Rio de Janeiro, 15 mar 1981. Acervo Pesquisa e Documentação MAM Rio.

9 BENJAMIN, Walter. Eduard Fuchs: Collector and Historian. Disponível em http://documents.mx/documents/benjamin-w-eduard-fuchs-collector-and-historian.html Acesso 25 fev 2016.

10 Idem, p. 223.

11 "É precisamente esta vontade de oscilar entre o presente e o futuro - sempre olhando para frente - que fez do MAM uma instituição tão dinâmica, inspiradora e necessária ao longo de sua história de 65 anos." CHATEAUBRIAND, Carlos Alberto Gouvêia. Coleção MAM Internacional. Rio de Janeiro: Barléu, 2014, p. 5. (grifo nosso). 


\section{Referências}

A GAZETA. Rio de Janeiro: 24 jul. 1978. Acervo Pesquisa e Documentação MAM Rio.

ARESTIZABAL, Irma. As Coleções do MAM/RJ. Segmentum Artis, ano I, n 1, 1987. Acervo Pesquisa e Documentação MAM-Rio. BELTING, Hans. O fim da história da arte: uma revisão dez anos depois. São Paulo: Cosac Naify, 2012.

BENJAMIN, Walter. Magia e técnica, arte e política. Ensaios sobre a literatura e a história. Obras escolhidas. Volume I. São Paulo: Editora Brasiliense, 1987.

CHANTAL, Georgel. O colecionador e o museu, ou como mudar a história da arte? Museologia e Interdisciplinaridade. Volume III, n. 6, março/abril, 2015. Disponível em http://www.eba.ufrj.br/ppgav/anacanti/pdf/georgel.pdf

DELEUZE, Gilles. GUATTARI, Félix. Geofilosofia. In: O que é a filosofia? São Paulo: Editora 34, 1992.

DIDI-HUBERMANN, Georges. Quando as imagens tocam o real. Pós. Belo Horizonte:, EBA/UFMG, v.2, n.4, p. $204-219$, nov. 2012. Disponível em http://www.eba.ufmg.br/revistapos/index.php/pos/article/viewFile/60/62

A arte morre, a arte renasce: a história recomeça (de Vasari a Winckelmann). In: A imagem sobrevivente: histórias da arte e tempo dos fantasmas segundo Aby Warburg. Rio de Janeiro: Contraponto, 2013.

. Diante do tempo: história da arte e anacronismos das imagens. Belo Horizonte: Editora UFMG, 2015.

FREUD, Sigmund. Carta 52. Edições Estandart Brasileira das Obras Psicológicas Completas de Sigmund Freud, Vol. 1. Rio de Janeiro: Imago, 1996.

LOWENTHAL, David. Como conhecemos o passado. Projeto História. São Paulo. n 17, nov. 1998. p. 63-201.

MALRAUX, André. Capítulo IV. In: O museu imaginário. Lisboa/Portugal: Edições 70, 2015, p. 175-263.

MUSEU de Arte Moderna do Rio de Janeiro. Exposição Permanente, 1953 (Catálogo) Acervo Pesquisa e Documentação MAM-Rio.

MUSEU de Arte Moderna do Rio de Janeiro. Rio de Janeiro: Banco Safra, 1999.

NORONHA, Fátima. Obras restauradas. Rio de Janeiro: Museu de Arte Moderna do Rio de Janeiro, 2014.

PROUST, Marcel. Em busca do tempo perdido. São Paulo: Nova Fronteira , 2014. 